\title{
Synoptic-scale ice-motion case-studies using assimilated motion fields
}

\author{
Walter N. Meier, ${ }^{1}$ James A. Maslanik ${ }^{2}$ \\ ${ }^{1}$ National Ice Center, FOB-4, Room 2301, 4251 Suitland Road, Washington, DC 20395, U.S.A. \\ ${ }^{2}$ Colorado Center for Astrodynamics Research, Aerospace Engineering Sciences Department, \\ University of Colorado, Boulder, CO 80309-0431, U.S.A.
}

\begin{abstract}
Observed and modeled sea-ice motions, combined via an optimal-interpolation assimilation method, are used to study two synoptic events in the Arctic. The first is a convergence event along the north Alaska coast in the Beaufort Sea during November 1992. Assimilation indicates stronger convergence than the stand-alone model, in agreement with Advanced Very High Resolution Radiometer-derived ice motions and Special Sensor Microwave/Imager-derived ice concentrations. The second event pertains to ice formation and advection in Fram Strait and the Barents and Greenland, Iceland and Norwegian Seas. Assimilation indicates export of thick, less saline ice out of the central Arctic into the East Greenland Sea. However, the model indicates little flow through Fram Strait, instead showing strong flow of thin, more saline first-year ice from the Barents Sea westward into the Greenland Sea. These results indicate that assimilation is a useful tool for investigating synoptic events in the Arctic and may be useful for both climate studies and operational analyses.
\end{abstract}

\section{INTRODUGTION}

Ice motion is an important component in the evolution of the polar ice cover and its role in Arctic climate. Divergent motion opens leads where heat and moisture transfer between the ocean and atmosphere is facilitated. Convergent motion results in ridged ice that can be several meters thicker than surrounding ice, affecting the ice mass balance and impeding navigation. Patterns of ice circulation in the Arctic also result in a transport of relatively fresh water, which is important for the formation of ocean water masses.

Long-term mean ice motion depends primarily on the average ocean currents and the wind forcing (Thorndike and Colony, 1982). On short time-scales, wind is the primary forcing component of ice motion. Thus, ice motion exhibits a transient component where ice direction and speed can dramatically deviate from the mean motion due to synopticscale weather systems.

Because of its transient nature, ice motion is particularly relevant for operational ice analyses and forecasts in the Arctic. Knowledge of when and where ice will exist in a given locale is crucial to a variety of human activities, such as military maneuvers, shipping and fishing endeavors and petroleum operations. Application of data assimilation is well suited for these types of operational ice-forecasting situations because it constrains model forecasts with observed data.

Here we apply a new data-assimilation methodology, combining ice-motion observations from buoys and passivemicrowave imagery with motion estimates from a sea-ice model to investigate two synoptic-scale events in the Arctic. The first is a convergence event in the Beaufort Sea, along the north coast of Alaska. The second deals with ice export out of the Barents Sea and Fram Strait.

\section{BACKGROUND}

Three primary approaches have been used to describe seaice motion: in situ measurements, remote-sensing observations and model simulations. Each approach has yielded valuable insights into the polar regions. However, each approach has limitations and none can fully describe Arctic processes at all scales.

In situ observations, while accurate, are sparse and often cover only short time series. This particularly limits their use for describing detailed spatial patterns of motion that can result from synoptic-scale systems, where only one observation, or none, may be available to represent the entire affected region (Kwok and others, 1998).

Satellite remote sensing allows the entire basin to be described on at least a daily basis. Visible and infrared Advanced Very High Resolution Radiometer (AVHRR) imagery has been used to map ice motion (e.g. Ninnis and others, 1986; Emery and others, 1991), but is limited by clouds. Synthetic aperture radar (SAR) imagery provides high-resolution ice-motion fields under all sky conditions (e.g. Kwok and others, 1990, 1995), but is limited by the swath width and orbit repeat cycle to 3-6 day intervals.

Passive-microwave imagery from the Special Sensor Microwave Imager (SSM/I) provides daily basin-wide coverage under all sky conditions (e.g. Agnew and others, 1997; Emery and others, 1997; Kwok and others, 1998; Liu and Cavalieri, 1998). However, SSM/I-derived ice motions suffer from low resolution $(12.5 \mathrm{~km})$ and problems with surface melt and atmospheric moisture during the polar summers.

Sea-ice models use dynamic and thermodynamic balances, and atmospheric and oceanic forcing to simulate ice motion (e.g. Hibler, 1979). Though temporal resolution can be quite high (typically 4-6 h time-steps or finer), spatial resolution (a maximum of about $10 \mathrm{~km}$ in the interior ice pack for con- 
tinuum-based models) has generally been poor. In addition, the model is constrained by the accuracy of the forcing and the assumptions of the model physics.

Data assimilation was first employed in the geosciences within atmospheric models (e.g. Charney and others, 1969). It has proven successful at constraining models to physical reality and improving forecast effectiveness (Ghil and Malanotte-Rizzoli, 1991). More recently, data-assimilation methods have been applied to ocean modeling (e.g. Kantha, 1995; Ullman and Wilson, 1998).

Assimilation studies involving sea-ice applications have been relatively few to date. The primary work was a series of papers that used a Kalman filter method to assimilate passivemicrowave data with a simple model of ice growth and transport (Thomas and Rothrock, 1989, 1993; Thomas and others, 1996). Though employing a simple model, the results demonstrated the ability of assimilation to produce more realistic estimates of ice concentration than from observations alone. Assimilation of observed ice motions into a high-resolution sea-ice model via a simple direct insertion demonstrated the potential of assimilating remotely-sensed ice velocities within standard, two-dimensional, dynamic-thermodynamic models (Maslanik and Maybee, 1994). The implementation of a more complex, optimal-interpolation method substantially reduced biases and errors in modeled and observed motions and produced a long time series of complete and more accurate assimilated ice motions (Meier and others, 2000). Here, we apply the ice-motion fields from these optimal-interpolation assimilation products to examine two synoptic events.

\section{METHODOLOGY}

\section{Observed motions}

Two sources of observed motions are used in this research. Ice motions are derived from daily composite SSM/I $85 \mathrm{GHz}$ imagery obtained from the U.S. National Snow and Ice Data Center (NSIDG) using a cross-correlation method (Emery and others, 1991). This method tracks a feature on a consistent grid over two succeeding images. The image resolution is $12.5 \mathrm{~km}$, which limits the ability to detect small motions on daily time-scales and results in a relatively "noisy" motion field. Oversampling and filtering methods were employed to improve the effective resolution. The final SSM/I motions are produced on a $60 \mathrm{~km}$ resolution grid. When compared to buoy observations, the daily rms motion error for the Arctic is on average $5-6 \mathrm{~cm} \mathrm{~s}^{-1}$, with a bias of $<0.5 \mathrm{cms}^{-1}$ (Meier and others, 2000). (Similar comparisons for the Southern Ocean (Heil and others, 2001) indicate larger biases in the Antarctic.)

Buoy motions are computed from daily buoy-location data obtained from the International Arctic Buoy Program (IABP). The rms motion error is dependent on the location error $( \pm 350 \mathrm{~m})$ and is approximately $0.5 \mathrm{~cm} \mathrm{~s}^{-1}$ for daily motions (Colony and Rigor, 1993).

\section{Model motions}

The model used in this research is a two-category sea-ice model with three ice classes based on age, an approximation of multiple thickness levels used in energy-budget calculations (Walsh and Zwally, 1990), a detailed surface albedo treatment (Ebert and Curry, 1993) and a viscous-plastic ice rheology. The model is forced with daily fields of pres- sure, temperature, downwelling longwave and shortwave radiation, and geostrophic winds from the U.S. National Centers for Environmental Prediction (NCEP) re-analysis fields (Kalnay and others, 1996). The model is centered at the North Pole and has $80 \mathrm{~km}$ gridcells (Maslanik and Dunn, 1997). Ice motions are calculated at $8 \mathrm{~h}$ time-steps and output daily.

\section{Assimilation method}

An optimal-interpolation assimilation method is employed to combine the observed and modeled ice motions using a weighted linear combination described by Equation (1):

$$
u_{k}^{\text {assim }}=u_{k}^{\text {model }}+\sum_{j=1}^{N} a_{k j}\left(u_{j}^{\text {obs }}-u_{j}^{\text {model }}\right) .
$$

Here, $u$ is the assimilated parameter (in this case the $u$ component of velocity), $k$ is the model gridpoint, and $j$ is one of $N$ observations in the neighborhood of the $k$ th model gridpoint. The weights, $a_{k j}$, are calculated from model and observation error covariances to minimize the estimate error. The Kalman filter method used in previous sea-ice assimilation studies (Thomas and Rothrock, 1993) is a generalized optimalinterpolation method where the error covariances are allowed to evolve with the model state. The simplification of using constant error covariances limits the effectiveness of the assimilation, but reduces the computational burden considerably and makes the use of detailed ice models practical.

The method described here is implemented with seasonally and regionally prescribed error covariances to improve the assimilation's effectiveness. It could have been implemented using daily error covariances for these synoptic, hindcast case-studies. However, the scheme was designed to be flexible for applications to longer time series and possible forecast studies (where the daily error covariances would not be known). Therefore, the methodology was not changed from its original form. Buoy observations are assimilated with their own, seasonally and regionally invariant, error covariances that reflect the more accurate error characteristics of the buoys. For more details on the assimilation methodology, see Meier and others (2000).

\section{RESULTS}

\section{Beaufort Sea, November 1992}

A previous research study on applications of combining multiple forms of data for study of the Arctic considered variability in sea-ice concentration as a function of ice transport in the Beaufort Sea in November 1992 using SSM/I and AVHRR imagery (W. N. Meier and others, 1997, http:// earthinteractions.org). On 19 November, AVHRR-derived ice motions combined with SSM/I-derived ice concentrations show a strong convergence event along the Canadian coast due to northerly winds arising from low pressure in the eastern Beaufort Sea (Fig. 1). Sea ice is advected toward the coast on the 19th, causing an increase in ice concentration. By the 20th, the coastal zone appears to be filled with ice, such that the southward drift into the Mackenzie River delta is deflected eastward and westward.

Here, we revisit that study using the assimilation methodology, comparing ice motions from the stand-alone model simulation with motions from the assimilation mode of the model. On 19 November, the stand-alone model shows some 

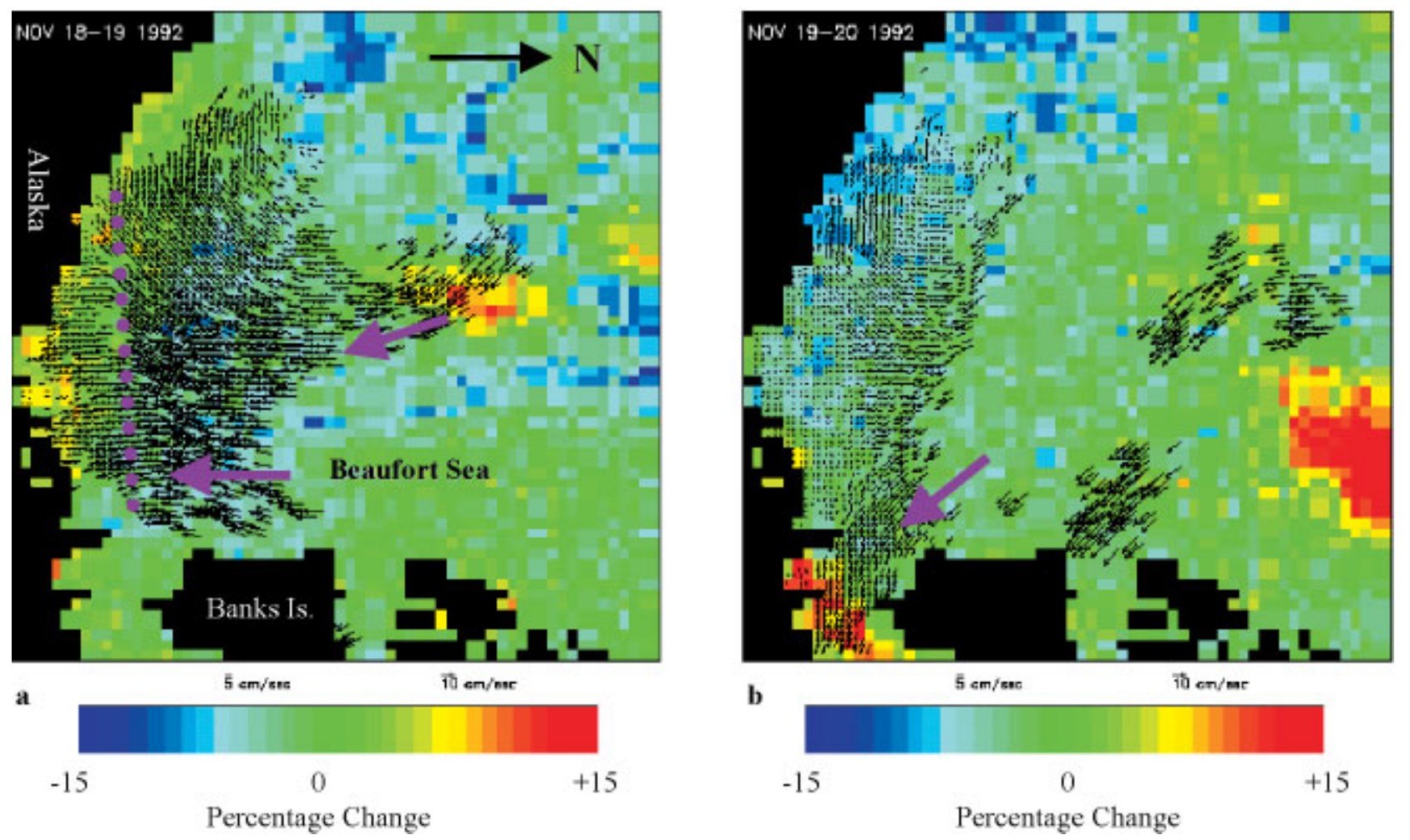

Fig. 1. AVHRR-derived ice motion and percentage change in SSM/I ice concentration from previous day for (a) 19 November 1992, and (b) 20 November 1992. The dotted line denotes a line of convergence where ice motion suddenly decreases. Adapted from W. N. Meier and others (1997, http://earthinteractions.org).

convergent motion along the Canadian coast (Fig. 2). However, there is a clear eastward component of the flow. This is because the NCEP pressure field indicates that the low pressure is substantially north of the coast. By 20 November, the model shows the convergent flow being retarded and more of the flow being deflected to the east and west. The assimilation case shows more southerly, convergent motion on the 19th than the standard model, with motion due south towards the coast and little eastward or western deflection of ice (Fig. 3). The assimilated motions indicate that the center of the pres- sure system is on the eastern Alaskan coast. By the 20th, the assimilated motions show the flow being deflected eastward. Thus, the assimilated motions yield better agreement with the higher-resolution AVHRR motions and the changes in the SSM/I ice concentrations. This is mostly due to the correction of errors in the NCEP atmospheric forcings by the assimilated motions, although errors in ocean currents and the model ice dynamics are also likely to be affected. The qualitative improvement shown by the assimilated motions (from SSM/I, buoys and model) here in comparison with
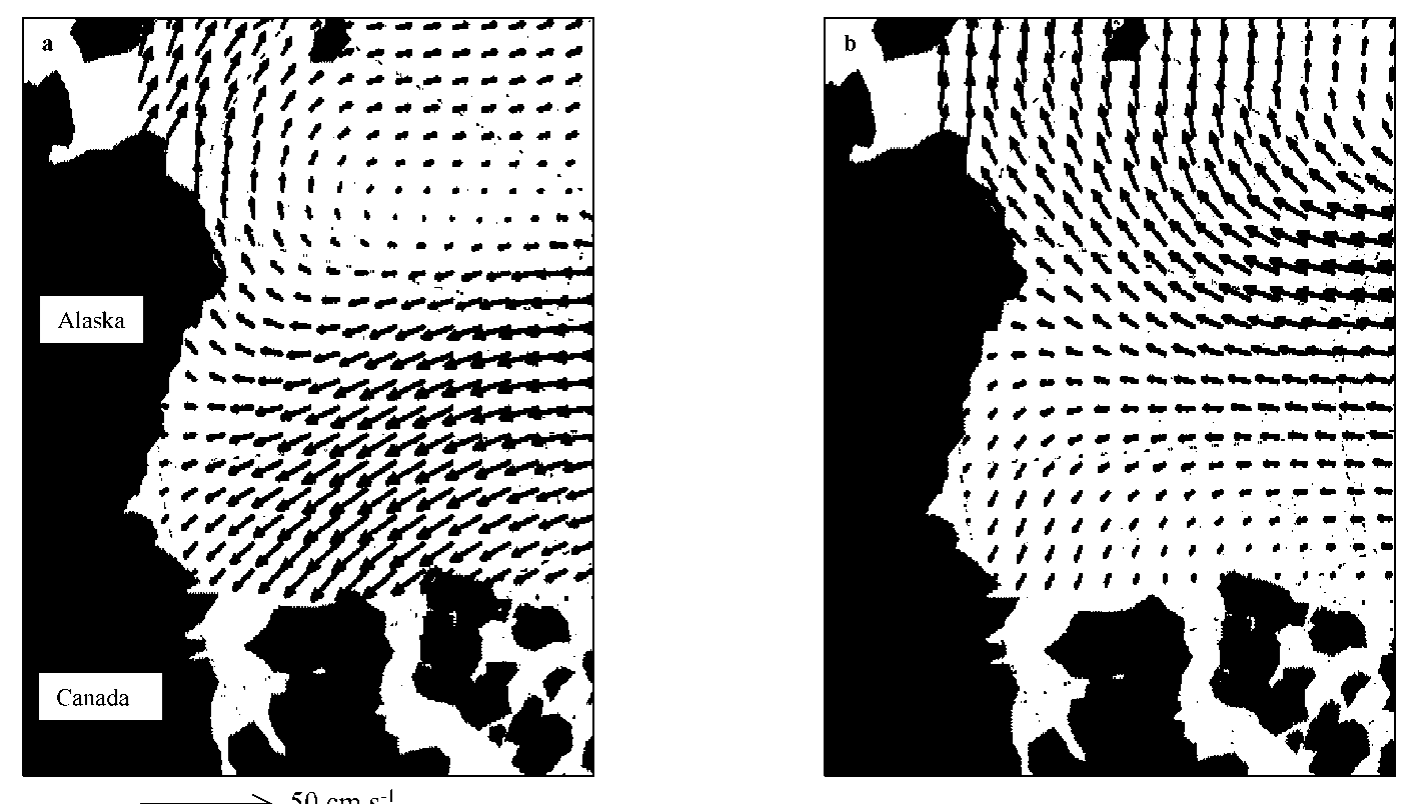

Fig. 2. Model ice motion in the Beaufort Sea on (a) 19 November 1992 and (b) 20 November 1992. 

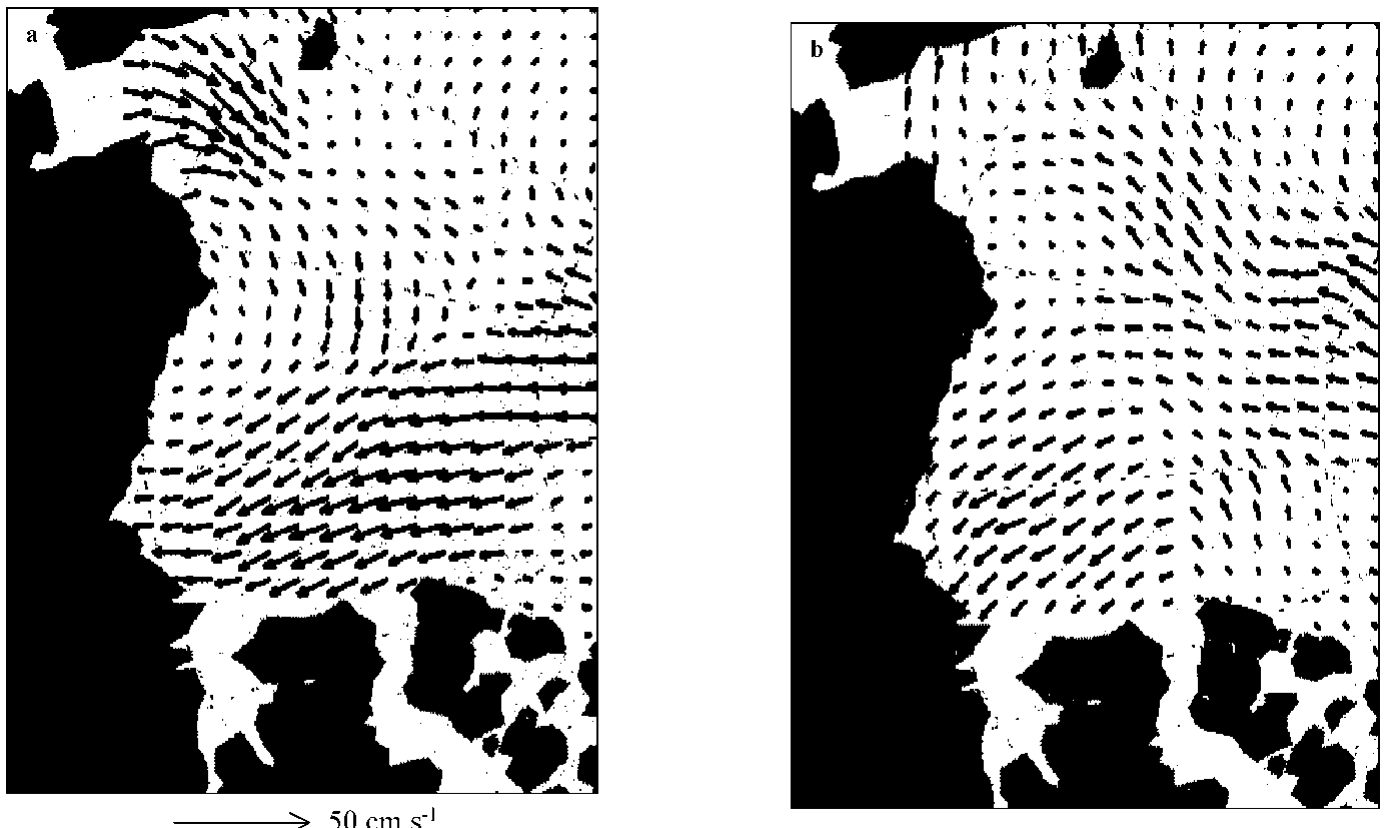

Fig. 3. Assimilated ice motion in the Beaufort Sea on (a) 19 November 1992 and (b) 20 November 1992.

the AVHRR motions recapitulates previous statistical analyses between SSM/I-model assimilated motions with buoy-observed motions (Meier and others, 2000).

Another interesting aspect of the flow occurs just north of the Bering Strait. While the model shows westward motion in the region on the 19 th, the assimilation case indicates a strong northward flow. This is the result of the apparent misplacement of high pressure in the western Beaufort by the NCEP forcings. By the 20th, both the assimilation and the model indicate southwestward flow near the Bering Strait.

Because the model is driven by NCEP pressure fields, the model's simulated ice advection does not produce as much convergence on 19 November as the assimilation case (Fig. 4). Since such convergence of the ice pack is a threat to navigation, coastal operations and military submarine activities, accurate simulation of such events is of particular interest.
Barents Sea/Fram Strait, March 1993

Ice export through Fram Strait is an important component of the Arctic sea-ice mass balance since most ice advection out of the Arctic occurs through Fram Strait. Ice that forms in the marginal ice zones in the coastal seas tends to be circulated into the central Arctic, growing and aging as it moves (Colony and Thorndike, 1984). Eventually, ice that does not melt during the Arctic summers is advected out of the Arctic, primarily through Fram Strait. After passing through Fram Strait, the ice enters the Greenland, Iceland and Norwegian (GIN) Seas where it meets warmer water from the North Atlantic and melts.

The Barents Sea is one such coastal region where a great deal of ice production occurs. Ice produced in the Barents may be advected northward into the central Arctic or west-
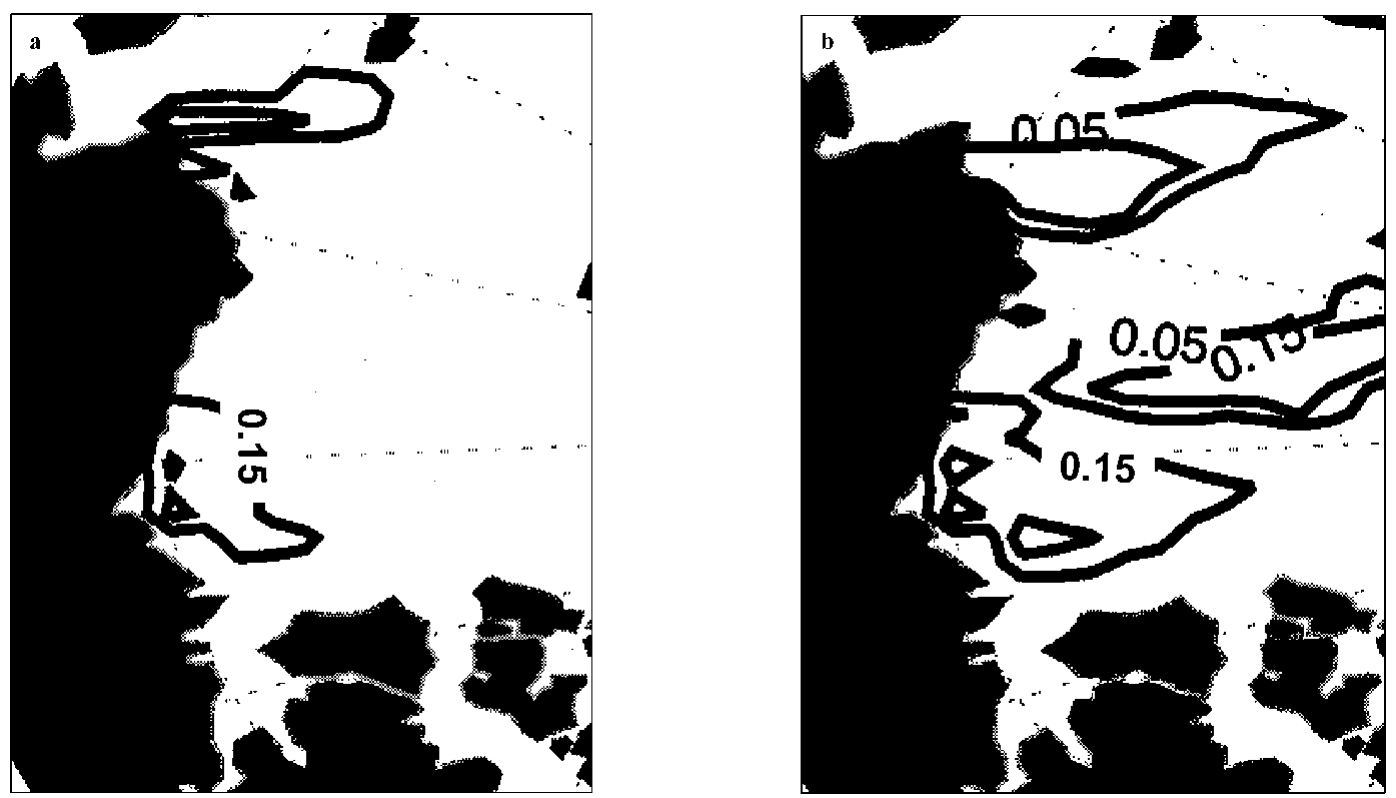

Fig. 4. Ice convergence in the Beaufort Sea on 19 November 1992 for ( a) model and (b) assimilation. Contour levels have units of $10^{6} s^{-1}$. 

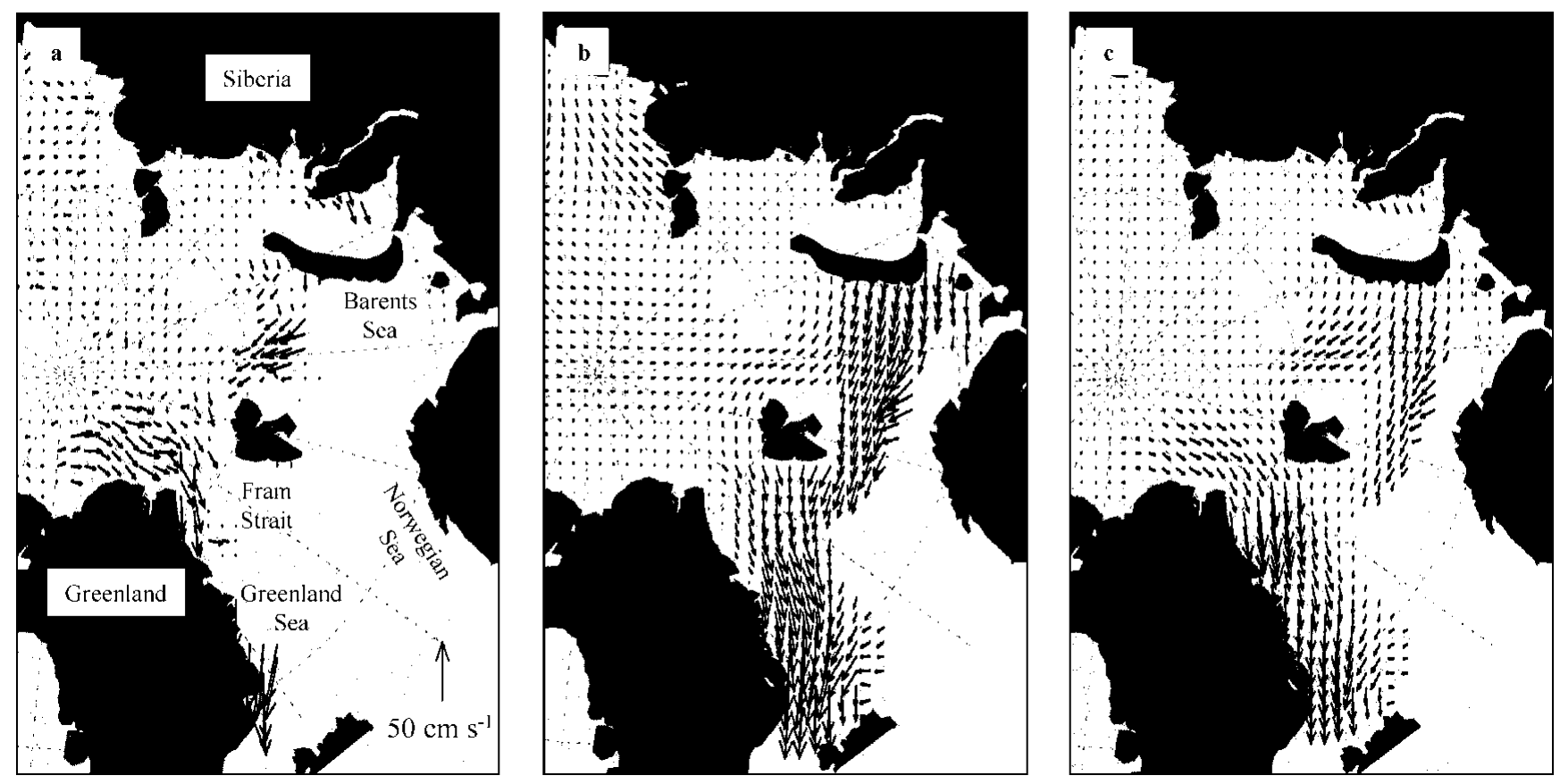

Fig. 5. Ice motion in the Fram Strait/Barents Sea region on 18 March 1993 for (a) SSM/I, (b) model and (c) assimilation.

ward into the GIN seas, depending on conditions. It is an important region in setting up the Arctic halocline, a layer of cold, saline stratified water that insulates the mixed layer and the overlying sea ice from the warm, saline Atlantic water mass (Aagaard and others, 1981). Changes in this region have been observed in the 1990s that suggest that the character of the formation and evolution of the halocline may be changing (Steele and Boyd, 1998). This could result in or be the result of changes in sea-ice cover, heat fluxes in the Arctic, and ocean circulation. In addition, the region encompasses important shipping routes and fishing sites. Knowledge of the drift of ice and the character of the ice (thin first-year vs thick multi-year) is important for route planning.

Here, we investigate ice motion in this region on 18 March 1993. A large discrepancy exists between the model and observed pattern of ice motion. SSM/I indicates typical ice motion in the region, with export of ice from the northern coast of Greenland through Fram Strait (Fig. 5a). This would primarily be thick, multi-year ice with low salinity. Thinner ice formed in the Barents Sea is shown to advect northward into the pack-ice region.

On the other hand, the model shows little export through Fram Strait (Fig. 5b). Flow is primarily westward from the Barents Sea and from the west coast of Svalbard. Thus, compared to the observed motions, much thinner and more saline ice is being advected into the GIN seas.

Through optimal-interpolation assimilation, the buoy and SSM/I observations constrain the model closer to observations (Fig. 5c). The assimilation case shows substantial outflow of ice from North Greenland through Fram Strait. The westward motion out of the Barents Sea is diminished, and northward motion is apparent, in agreement with the observations.

Because of increased outflow from the central Arctic, assimilation yields greater ice export through Fram Strait. The model yields an export of $0.10 \mathrm{~Sv}$ on $18 \mathrm{March}$, while assimilation yields over twice as much export, $0.21 \mathrm{~Sv}$.

Though this is only a 1 day case-study, it illuminates the ability of assimilation to use improved ice-motion fields to study synoptic-scale motion patterns. These synoptic events could have seasonal consequences for the character of the ice cover in the region. A previous study indicates that the model consistently underestimates ice export through Fram Strait compared to the assimilated case over the course of several years (Meier and others, 2000). Models are commonly used to study ice export through Fram Strait (e.g. Harder and others, 1998) and halocline and deep-water formation (e.g. Goosse and Fichefet, 1999). Assimilation indicates that use of observations may help to remove model biases and errors in forcings, constraining them closer to physical reality and yielding better insights into important ice-formation and melt processes in the region.

\section{GONGLUSION}

Synoptic-scale events in the Arctic Ocean can cause sudden changes in the patterns of ice motion. These changes can result in the formation of leads where heat and vapor transfer is facilitated. Convergent motion can cause ridging, affecting the ice mass balance and impeding operational activities.

Here, we demonstrated, via two example case-studies, the utility of data assimilation to combine observed and modeled motions to better characterize such events. The assimilated model simulates a convergence event along the north Alaskan coast that is indicated by AVHRR-derived ice motions and SSM/I ice concentrations. In the Fram Strait/Barents Sea region, the assimilated model simulates high inflow into the GIN seas from the central Arctic through Fram Strait and low inflow from the Barents Sea.

In both of these case-studies, assimilation substantially reduces errors in the estimates of ice motion and improves derived products of ice convergence and Fram Strait icevolume export. The more accurate representation of these synoptic events demonstrates the utility of a data-assimilation approach for a variety of regional Arctic studies. 


\section{ACKNOWLEDGEMENTS}

This work has been supported by the NASA Mission to Planet Earth Fellowship Program (NASA NGT-5-30034), the University Corporation for Atmospheric Research Visiting Scientist Program and NASA grant NAG-6820. SSM/I and buoy data were obtained from the NSIDC and the IABP. The U.S. National Oceanic and Atmospheric Administration/NASA Polar Pathfinder projects provided AVHRR ice-motion and additional data. Thanks to the reviewers for their helpful comments.

\section{REFERENCES}

Aagaard, K., L. K. Coachman and E. C. Carmack. 1981. On the halocline of the Arctic Ocean. Deep-Sea Res., Ser. A, 28, 529-545.

Agnew, T. A., H. Le and T. Hirose. 1997. Estimation of large-scale sea-ice motion from SSM/I 85.5 GHz imagery. Ann. Glaciol., 25, 305-311.

Charney, J., M. Halem and R. Jastrow. 1969. Use of incomplete historical data to infer the present state of the atmosphere. 7. Atmos. Sci., 26, 11601163.

Colony, R. L. and I. G. Rigor. 1993. International Arctic Ocean Buoy Program data report for 1 January-31 December 1992. Seattle, WA, University of Washington. Applied Physics Laboratory. (Tech. Mem. PL-UWTM 29-93.)

Colony, R. and A. S. Thorndike. 1984. An estimate of the mean field of Arctic sea ice motion. F. Geophys. Res., 89(C6), 10,623-10,629.

Ebert, E. E. and J. A. Curry. 1993. An intermediate one-dimensional thermodynamic sea ice model for investigating ice-atmosphere interactions. $\mathcal{F}$. Geophys. Res., 98 (C6), 10,085-10,109.

Emery, W. J., C.W. Fowler, J. Hawkins and R. H. Preller. 1991. Fram Strait satellite image-derived ice motions. F. Geophys. Res., 96(C3), 4751-4768. (Correction: 7. Geophys. Res., 96(C5), 1991, 8917-8920.)

Emery, W. J., C. W. Fowler and J. A. Maslanik. 1997. Satellite-derived maps of Arctic and Antarctic sea-ice motion. Geophys. Res. Lett., 24(8), 897-900.

Ghil, M. and P. Malanotte-Rizzoli. 1991. Data assimilation in meteorology and oceanography. Adv. Geophys., 33, 141-266.

Goosse, H. and Th. Fichefet. 1999. Importance of ice- ocean interactions for the global ocean circulation: a model study. f. Geophys. Res., 104(C10), 23,337-23,355.

Harder, M., P. Lemke and M. Hilmer. 1998. Simulation of sea ice transport through Fram Strait: natural variability and sensitivity to forcing. $\mathcal{F}$. Geophys. Res., 103 (C3), 5595-5606.

Heil, P., C.W. Fowler, J. A. Maslanik, W.J. Emery and I. Allison. 2001. A comparison of East Antarctic sea-ice motion derived using drifting buoys and remote sensing. Ann. Glaciol., 33 (see paper in this volume).

Hibler, W. D., III. 1979. A dynamic thermodynamic sea ice model. F. Phys.
Oceanogr., 9(7), 815-846.

Kalnay, E. and 21 others. 1996. The NCEP/NCAR 40-year reanalysis project. Bull. Am. Meteorol. Soc., 77(3), 437-471.

Kantha, L. 1995. Barotropic tides in the global oceans from a nonlinear tidal model assimilating altimetric tides. 1 . Model description and results. 7 . Geophys. Res., $\mathbf{1 0 0}(\mathrm{Cl} 2), 25,283-25,308$.

Kwok, R., J. C. Curlander, R. McConnell and S. S. Pang. 1990. An ice-motion tracking system at the Alaska SAR facility. IEEE 7. Oceanic Eng., OE-15(1), 44-54.

Kwok, R., D. A. Rothrock, H. L. Stern and G. F. Cunningham. 1995. Determination of the age distribution of sea ice from Lagrangian observations of ice motion. IEEE Trans. Geosci. Remote Sensing, GE-33(2), 392-400.

Kwok, R., A. Schweiger, D. A. Rothrock, S. Pang and C. Kottmeier. 1998. Sea ice motion from satellite passive microwave imagery assessed with ERS SAR and buoy motions. F. Geophys. Res., 103(C4), 8191-8214.

Liu, A. K. and D. J. Cavalieri. 1998. On sea ice drift from the wavelet analysis of the Defense Meteorological Satellite Program (DMSP) Special Sensor Microwave Imager (SSM/I) data. Int. F. Remote Sensing, 19(7), 1415-1423.

Maslanik, J. and J. Dunn. 1997. On the role of sea-ice transport in modifying Arctic responses to global climate change. Ann. Glaciol., 25, 102-106.

Maslanik, J. A. and H. Maybee. 1994. Assimilating remotely-sensed data into a dynamic-thermodynamic sea ice model. In Stein, T. I., ed. IGARSS'94. Surface and Atmospheric Remote Sensing: Technologies, Data Analysis and Interpretation, Pasadena, California, USA, August 8-12, 1994. Proceedings. Vol. 3. Piscataway, NJ, Institute of Electrical and Electronics Engineers, 1306-1308.

Meier, W. N., J. A. Maslanik and C.W. Fowler. 2000. Error analysis and assimilation of remotely sensed ice motion within an Arctic sea ice model. f. Geophys. Res., 105(C2), 3339-3356.

Ninnis, R. M., W. J. Emery and M. J. Collins. 1986. Automated extraction of pack ice motion from advanced very high resolution radiometer imagery. 7. Geophys. Res., 91 (C9), 10,725-10,734.

Steele, M. and T. Boyd. 1998. Retreat of the cold halocline layer in the Arctic Ocean. 7. Geophys. Res., 103(C5), 10,419-10,435.

Thomas, D. R. and D. A. Rothrock. 1989. Blending sequential scanning multichannel microwave radiometer and buoy data into a sea ice model. 7. Geophys. Res., 94(C8), 10,907-10,920.

Thomas, D. R. and D. A. Rothrock. 1993. The Arctic Ocean ice balance: a Kalman smoother estimate. F. Geophys. Res., 98(C6), 10,053-10,067.

Thomas, D., S. Martin, D. Rothrock and M. Steele. 1996. Assimilating satellite concentration data into an Arctic sea ice mass balance model, 1979-1985. 7. Geophys. Res., 101(C9), 20,849-20,868.

Thorndike, A. S. and R. Colony. 1982. Sea ice motion in response to geostrophic winds. 7. Geophys. Res., 87(C8), 5845-5852.

Ullman, D. S. and R. E. Wilson. 1998. Model parameter estimation from data assimilation modeling: temporal and spatial variability of the bottom drag coefficient. F. Geophys. Res., 103(C3), 5531-5549.

Walsh, J. E. and H. J. Zwally. 1990. Multiyear sea ice in the Arctic: modeland satellite-derived. 7. Geophys. Res., 95(C7), 11,613-11,628. 